We are indebted to Messrs. Schering Corporation, Montreal, for generous gifts of hormones.

V. E. GaRdiner

W. E. PhXLIIPS

W. A. MaW

R. H. Common

Department of Chemistry,

Macdonald College,

Province of Quebec.

Feb. 18. ${ }^{1}$ Neff, A. W., Parrish, D. B., Hughes, J. S., and Payne, L. F., Arch.

${ }^{2}$ Parrish, D. B., Williams, R. N., and Sanford, P. E., Arch. Biochem. and Biophys., 34, 64 (1951).

${ }^{3}$ Chapman, D. G., Gluck, M., Common, R. H., and Maw, W. A. Canad.

4 Narod, M., and Verhagen, D., Anal. Chem., 20, 627 (1948).

"Hertz, R., Jarsen, C. D., and Tullner, W., J. Nat. Cancer Inst., 8, $123(1947)$ - Keefe, T. J., thesis approved for degree of M.Sc., McGill University
(1951).

\section{Absorption from Intestine of Rats with Blind Self-filling Pouch}

IT has been shown by Watson, Cameron and Witts ${ }^{1}$ that macrocytic anæmia develops in rats in which a blind self-filling intestinal pouch has previously been formed. They were unable ${ }^{2}$, however, to demonstrate any anatomical or histological lesion in the alimentary tract. Toon ${ }^{3}$ found that treatment with aureomycin prevented the appearance of anæmia in 100 per cent of rats, adding weight to Witt's suggestion that the anæmia might be due in some way to the bacterial content of the pouch. Nevertheless, Aitken, Badenoch and Spray found a deficiency in fat absorption in rats so operated, whether or not anæmia had developed.

It was thought that it might be of interest to study the absorption of glucose and an amino-acid from the intestine of rats treated thus.

Blind self-filling pouches were formed, as described by Cameron, Watson and Witts ${ }^{1}$, at approximately $40 \mathrm{~cm}$. from the ileo-cæcal valve and of approximately $15 \mathrm{~cm}$. in length. The animals were fed on ordinary diet throughout. The acute experiments were carried out eight to ten weeks after operation, since it was found that at this time the hæmoglobin had fallen from the normal 100-110 per cent to an average of 80 per cent (Haldane). In one set of experiments, absorption of glucose in operated rats was compared with that in a group of normals; absorption of L-glutamic acid was compared in a further series of operated and normal rats.

Intestinal loops were prepared as described by Gibson and Wiseman ${ }^{5}$. In operated animals, these were formed just proximal to the orifice of the cul-desac, and in normal animals at a corresponding distance from the ileo-cæcal valve. In the first series, $1 \mathrm{ml}$. of glucose solution containing $100 \mathrm{mgm}$. was administered and the sugar content of the fluid in the loop estimated after $1 \mathrm{hr}$., by the method of Nelson ${ }^{6}$; in the second series, $1 \mathrm{ml}$. solution containing $37.8 \mathrm{mgm}$. L-glutamic acid (sodium salt) was administered and the loop fluid analysed again after $1 \mathrm{hr}$., by the method of Pope and Stevens?.

In neither set of experiments was there any significant difference in absorption between normal and operated rats. In the glucose experiments, normals showed a mean absorption of $68.4 \mathrm{mgm} . / \mathrm{hr}$. compared with $67 \cdot 3 \mathrm{mgm}$./ hr. for operated animals; the standard error of the difference was $\pm 9 \cdot 1$. In the glutamic acid experiments the figures were $27 \cdot 4$ and $27.0 \mathrm{mgm} . / \mathrm{hr}$. respectively, the standard error of the difference being $\pm 2 \cdot 0$. The variability was such as not to be appreciably affected by the fact that not all loops as finally measured were exactly $15 \mathrm{~cm}$. long. There was no correlation between absorption and weight of rat, or-in the case of operated animals-alteration in weight.

The above experiments, then, provide no evidence that the absorption of glucose and glutamic acid from a blind self-filling intestinal pouch is significantly different from that from normal intestine.

I am indebted to Miss M. Creasy, of the Department of Statistics, University of Aberdeen, for the statistical analysis.

Department of Physiology,

University of Aberdeen. Feb. 22.

${ }^{1}$ Watson, G. M., Cameron, D. G., and Witts, L. J., Blood, 4, 803 (1949). Cameron, D. G., Watson, G. M., and Witts, L. J., Brit. J. Exp. Path., 31, 349 (1950).

${ }^{3}$ Toon, R., Proc. Soc. Exp. Biol. Med., 75, 762 (1950). - Aitken, Moira A., Badenoch, J., and Spray, G. H., Brit. J. Exp.

${ }^{5}$ Gibson, Q. H., and W iseman, G., Biochem. J., 48, 426 (1951).

${ }^{5}$ Nelson, N., J. Biol. Chem., 153, 375 (1944).

' Pope, C. G., and Stevens, M. F., Biochem. J., 38, ii, 1070 (1939).

\section{Thin-Film Interferometric Techniques for High-Magnification Topographical Studies}

Teis communication describes a simple interferometric technique for examination of surface topography without the use of optical flats, the particular advantage being the possibility of using high magnification in extension across the surface without the use of a complex interference microscope. The techniques are based upon the production of a thin transparent film of Canada balsam on the surface. A drop of Canada balsam dissolved in benzine is placed on the surface and, after spreading, dries as a thin film. The spreading is assisted by a touch of cedar wood oil. The thin film appears to follow closely the contour of the lower surface, while taking on a reasonably flat upper surface, although wrinkling can at times be detected. Illumination with monochromatic light leads to the production of an interference picture which exhibits some degree of multiple-beam interference and, as the film is very thin, high resolution, using up to $3-\mathrm{mm}$. dry objectives, can be used. Thus it is possible to examine interferometrically with simultaneous high magnification in extension, a condition not normally realizable with a multiple-beam equipment employing optical flats.

The wrinkling or curvature of the surface of the film, which is irrelevant to the topography under study, restricts the application of the method largely to the study of discontinuities, at which any spurious topography due to surface curvature does not invalidate conclusions drawn as to the heights of the discontinuous steps. Order allocation is readily obtained by using different wave-lengths, and the direction of the steps by arranging the surface film to be wedged in a suitable direction. The method has the merit that it can be used on relatively inaccessible regions of crystals.

Fig. 1 ( $\times 600$ in extension) shows growth steps on a silicon carbide crystal. Fig. $2(\times 1,800$ in extension) shows the interferogram given by growth trigon on a natural (111) diamond octahedron face. This is of considerable interest in that it reveals a 'trench' 